\title{
Electroretinographic Recordings from the Isolated and Superfused Murine Retina
}

\author{
Alnawaiseh Maged, Albanna Walid, Banat Mohammed, \\ Abumuaileq Ramzi, Hescheler Jürgen and Schneider Toni \\ University of Cologne \\ Institute of Neurophysiology \& Center for Molecular Medicine Cologne (CMMC)
}

Germany

\section{Introduction}

Vertebrate retina has routinely been isolated from bovine [1-4] or rat eyes [5]. However, many animal models for disturbances in neuronal signalling rely on gene inactivation or transgenes in mice. To get access to the isolated retina from these model systems to investigate neuronal processing, the technique of retina isolation and recording in a closed chamber was transferred from the bovine to the murine eye.

The ERG recordings of the isolated and superfused retina from bovine eye were most successfully performed in a closed recording chamber, in which a defined and controlled oxygen concentration can be achieved. Under these conditions, repetitive ERG recordings (interval time $5 \mathrm{~min}$ ) can be performed up to 10 hours [4]. For rat and murine ERG recordings an open system was introduced recently, in which oxygen may escape easier, and stable recordings were shortened to about $90 \mathrm{~min}$ [6]. Therefore, we tried to optimize murine ERG recordings in the same closed system as it was introduced for frog and bovine retina $[7 ; 8]$.

\section{Optimization of murine ERG recordings and applications}

In the first section the history to optimize murine ERG recordings will be described for the last six years, in which initially an incomplete ERG was recorded, which was mainly dominated by the a-wave. After changes for the retina isolation as well as for the recording conditions, a full ERG was obtained, which even could be subdivided for the b-wave response into at least two different fractions [9].

Finally, two important topics will be covered for successful ERG recordings. (i) Using still the bovine retina, it will be analysed that a trace metal free solution can be achieved by using a tricine-based buffer system, which chelates heavy metal divalent cations selectively. Such a buffering may be very helpful for ERG recordings in the presence of submicromolar copper ion concentrations, which may be as important as investigations with the artificial $\mathrm{Ni}^{2+}$-ions [3;10] or the native occurring $\mathrm{Zn}^{2+}$-ions [11]. (ii) Flashes of high light intensity will be used to trigger repetitive ERG responses and to test the stability of the optimized murine ERG recording conditions. 


\subsection{Development of methods to record full murine ERGs for basal and reciprocal signalling}

The diameter of a murine eye (male, 10 - 15 weeks of age) is about 10-fold smaller than the diameter of the bovine eye (age of 9 - 12 month). Therefore, an optimal isolation procedure is critical for subsequent successful and stable ERG recordings from the isolated murine retina.

In the following three chapters, we introduce three different procedures, which were used in our laboratory to realize and to improve the reproducible ERG recording from the murine retina.

The first procedure, the retina isolation by a rotating razor blade, was used to mimic the way of working as done with the bovine retina. Instead of using a knife to open up the eye bulb, we added a razor blade to a rotator, which cut the murine eye bulb laying in the stator very harsh, as we noted later. Under these conditions, the ERG recordings were dominated by the a-wave.

The second and the third procedure used a more gentle way to open up the eye bulb. The access to the retina was achieved by opening up the eye bulb at the level of the cornea. Consecutively, the lens was removed, and the eye cup was gently cut apart. The second and the third procedure differ with respect to the waiting time, after which ERG recordings were started. Initially (second procedure), we realized that a full ERG was better achieved by incubating the retina in nutrient solution for four hours in darkness. One may assume that it recovered from the ischemic conditions during the isolation procedure. Although basic signalling recovered during these 4 hours, reciprocal signalling obviously vanished. Therefore, we omitted preincubation, and started immediately (third procedure).

The main focus of our research was directed to understand the mechanisms of reciprocal signalling via voltage-gated $\mathrm{Ca}^{2+}$ channels, sensitive to heavy metal cations $\left(\mathrm{Ni}^{2+}, \mathrm{Zn}^{2+}\right.$, $\mathrm{Cu}^{2+}$ ). It was started first by using $\mathrm{NiCl}_{2}$, an often used non-selective $\mathrm{Ca}^{2+}$-channel blocker with some preference for $\mathrm{Ca}_{\mathrm{v}} 2.3 / \mathrm{R}$-type and for $\mathrm{Ca}_{\mathrm{v}} 3.2 / \mathrm{T}$-type $\mathrm{Ca}^{2+}$ channels, which have $\mathrm{IC}_{50}$ values at $10 \mu \mathrm{M}$. Therefore, an optimal recording of only basal retinal signal transduction was not sufficient, and we had to pay attention to more favourable conditions for ERG recording, preserving also signalling via feedback from amacrine cells to bipolar neurons.

\subsubsection{Retina isolation by a rotating razor blade}

Initial preparations of the murine retina followed the idea that the eye bulb should be opened up in a similar way as for the bovine retina by cutting the eye bulb at the ora serrata region. Therefore, a rotating razor blade was used, which led fast and reproducibly to a nearly full sized retina, isolated from the proximal cup of the remaining eye bulb. Under these conditions, it was possible to record photoreceptor responses reliably for at least 90 min [12]. Interestingly, from the incomplete ERG, which was characterized by a large awave (Fig. 1A - 1C), the photoreceptor response was sensitive towards low concentrations of dihydropyridines ( $25 \mathrm{nM}$ racemic isradipine). Under similar recording conditions, the bovine photoreceptor response was insensitive even towards $2 \mu \mathrm{M}$ isradipine [12].

Detailed analysis of the mechanism for dihydropyridine sensitivity of the murine photoreceptor response (a-wave) led to the detection that preincubation of the murine retina in $1-10 \mathrm{mM}$ D-aspartate, a well known antagonist of transsynaptic signalling [13], eliminated the sensitivity towards this classical L-type $\mathrm{Ca}^{2+}$ channel antagonist. Similarly, also the sensitivity of the a-wave towards the T-type $\mathrm{Ca}^{2+}$ channel antagonist mibefradil (1 - 
$10 \mu \mathrm{M})$ was reversibly occluded by D-aspartate preincubation leading to the conclusion that minor transsynaptic signal transduction was present before aspartate application [12]. Such a very minor $b$-wave component could be deduced from our recordings by subtracting the mean values of murine ERGs in the presence of aspartate $(1 \mathrm{mM})$ from those ERGs initially recorded before applying aspartate (Fig. 1D).
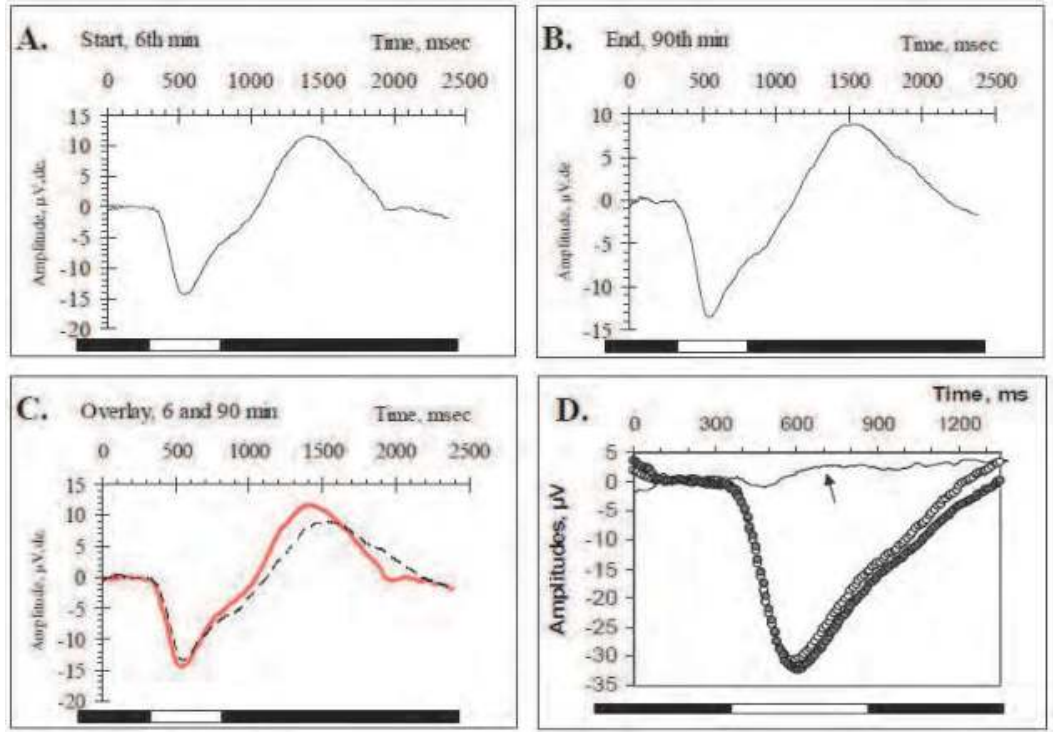

Fig. 1. Murine ERGs from isolated retinas of "razor-blade" isolated retina. The retina was dark-adapted and the electroretinogram was elicited by a single white flash at intervals of 3 $\mathrm{min}$. The flash intensity was initially set to $6.3 \mathrm{~lx}$ (Fig. 1 and procedure 1 ) at the retinal surface using calibrated neutral density filters with light stimulation lasting $500 \mathrm{~ms}$ (see bar under the ERG traces), controlled by a timer operating a mechanical shutter system. Later (procedure 2 and 3) the flash intensity was raised to $63 \mathrm{mlx}$. During all conditions, the ERG was recorded by using two silver/silver-chloride electrodes, which are on both sides of the recording chamber. The ERG was amplified and bandpass limited between 1 and $300 \mathrm{~Hz}$. The signal was AD converted and stored using a PC-based signal acquisition and analysis system. Temperature was $30^{\circ} \mathrm{C}$ (procedure 1 ), and $27.5^{\circ} \mathrm{C}$ (procedure 2 and 3 ). Flow rate for nutrient solution (Sickel solution) was $1 \mathrm{ml} / \mathrm{min}$ (procedure 1), and $2 \mathrm{ml} / \mathrm{min}$ (procedure 2 and 3). A. ERG recorded 6 min after begin of superfusion of nutrient solution. B. ERG recorded $90 \mathrm{~min}$ after begin of superfusion of nutrient solution. C. Superposition of traces from panel A. and B. The dashed line represents the ERG trace after $90 \mathrm{~min}$ of superfusion. Panel A. - C. represents data from the same experiment. D. ERG traces before (open circles) and after superfusion of $1 \mathrm{mM} \mathrm{D}$-aspartate for $30 \mathrm{~min}$ (filled circles). The difference between both traces was calculated (thin line).

Overall, under the conditions of razor-blade isolated retina it was impossible to record a full ERG with a "healthy" b-wave component, as it was routinely observed for the isolated bovine retina in the same setup system. Therefore, the isolation protocol was changed completely. 


\subsubsection{Retina isolation under more gentle conditions followed by a preincubation period}

The isolation of the murine retina was changed in a way that mechanical stress was reduced. In a well documented approach, the murine retina was isolated by opening up the eye bulb from the anterior side by dissecting the cornea, and by explanting the eye lens first [14]. We assume that the rotating razor blade in the former procedure may have introduced too much mechanical tension on the retina leading to a trauma and a loss of full transretinal signalling capacity. The new isolation procedure can be followed up in a detailed animation, which is available in the internet as a supplement [14]. In short, enucleated murine eyes (Fig. 2)
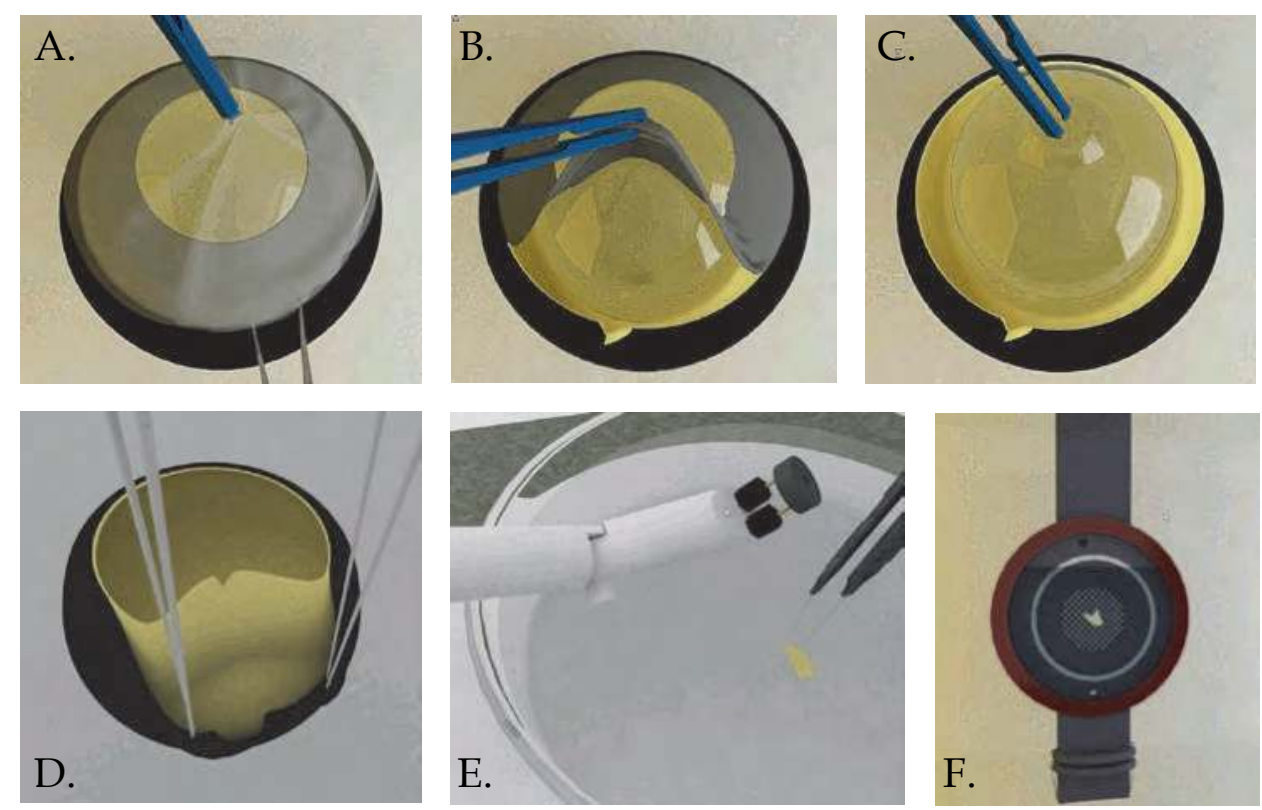

Fig. 2. Isolation of murine retina segments for ERG-recordings by opening up the eye bulb from the front side of the eye. The pictures are taken from a detailed animation (generated by Nadeen Albanna), which can be watched in the supplement of the related publication [14].A. The extirpated eye cup was initially treated with a 27 gauge needle from the front side to relief the tension. The cornea is used to hold the eye cup by fixing it via a lancette. The cornea will be partially separated. B. A triangled cut is incised into the sclera, reaching down to the ora serrata region. A forceps is moved through the triangle cut to remove the iris (for details of the used tools refer to [14]). C. After removing the iris, the lens will be taken off, and the opened eye is gently moved within the nutrient solution to tear off gently the retina from the underlying pigment epithelium. D. Next, two forceps are used to open up the sclera layers by tearing it apart at the site of initial incision. The retina usually stays intact, and can be cut into up to $4-6$ pieces. E. The white supporting lever arm is connected with a $3 \mathrm{~mm}$ in diameter facing ring, to which the retina can be attached. It is held by surface tension to the ring and covers the central hole of $1 \mathrm{~mm}$ diameter. F. The retina-loaded support system is moved to the recording chamber, and docked into the central hole of the gasket. The recording chamber is closed by rubber rings, glas plates and interconnecting metal rings. 
were placed into nutrient solution, fixed by a lancette and opened from the front side first by punching a tiny hole through the cornea to relieve the aqueous humour from the anterior and posterior chamber of the eye, and thus, to reduce the tension (Fig. 2A). Thereafter, the cornea was removed, and the iris disconnected, and a tiny triangle shaped incision was made into the sclera (Fig. 2B) for an easier separation later of the proximal eye cup, and for the immediate introduction of a small forceps. Finally, the lens was carefully removed (Fig. 2C). Consecutively, the opened eye-cup was held and separated apart by a forceps in order to detach the retina from the pigment epithelium by repetitive moving in the nutrient solution (Fig. 2D). The successive separation of the retina from the pigment epithelium has to be performed gently, and is supported by the cutting of the sclera layers from the outside. Finally, the isolated retina may be divided into $4-6$ segments.

One of the posterior retina segments was finally mounted on a plastic mesh occupying the centre of the perfusing chamber by using a supporting tool (Fig. 2E). The ring, fixed by the submerged lever tool, is loaded with a retina segment, which was stored floating in the oxygenized nutrient solution. It is touched with the forceps at the region where formally the fibres of the N. opticus had left the eye cup. The retina segment adheres by itself and the supporting lever is turned upside down to move the retina loaded ring into the holder of the recording chamber (Fig. 2F). The view from the underlying nylon mesh further visualizes one of the two silver/silver-chloride electrodes, which are on both sides of the recording chamber. After closing the chamber by two gaskets and two glasses, the nutrient solution is perfused over the front and the rear side (Fig. 2F) of the recording chamber.

Based on the more gentle isolation procedure, full ERG recordings could be achieved, and optimal conditions for the recordings for mice were summarized and published [14]. For example, light intensity for scotopic ERG recordings was as low as $6.3 \mathrm{mlx}$ for the bovine retina but 10 -fold higher for the murine retina.

ERG recordings even in the presence of low $\mathrm{NiCl}_{2}$ concentrations (up to $50 \mu \mathrm{M}$ ) could be easily followed up for several hours without loosing a full b-wave response (Fig. 3B).
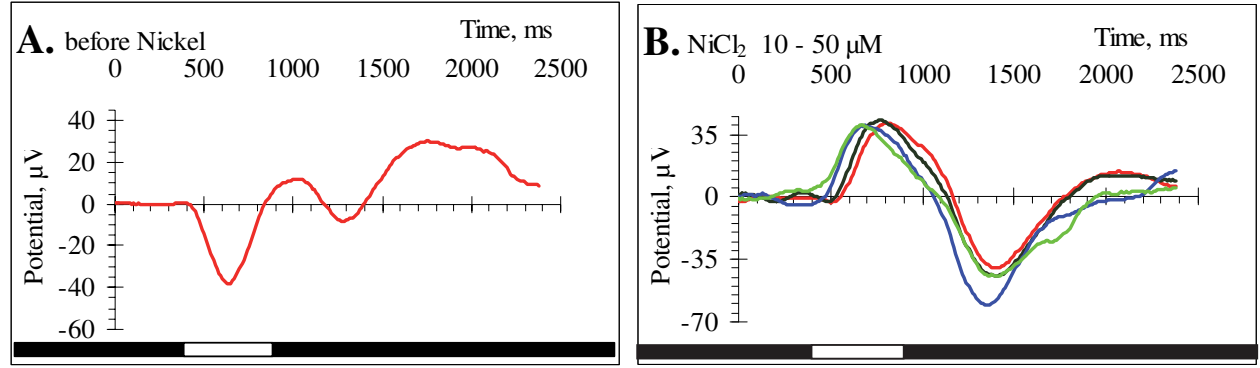

Fig. 3. Murine ERGs, which were recorded after gentle retina isolation and a 4 hour preincubation period. Light flashes were given at $63 \mathrm{mlx}$ for $0.5 \mathrm{sec}$ (see bar under the ERGs). Temperature was $27.5^{\circ} \mathrm{C}$. Flow rate for nutrient solution (Sickel solution) was $2 \mathrm{ml} / \mathrm{min}$. A. Early registration of ERG in the absence of $\mathrm{NiCl}_{2}$. Recording was started 30 min after loading the recording chamber. B. Full ERGs after $\mathrm{NiCl}_{2}$ superfusion. Superposition of ERG traces after $60 \mathrm{~min}$ (red line, $10 \mu \mathrm{M} \mathrm{NiCl}_{2}$ ), 86 min (black line, $15 \mu \mathrm{M} \mathrm{NiCl}_{2}$ ), 150 min (blue line, $50 \mu \mathrm{M} \mathrm{NiCl}_{2}$ ), and $215 \mathrm{~min}$ (green line, $50 \mu \mathrm{M} \mathrm{NiCl}_{2}$ ). 
Usually, the murine retina needed a while before a full ERG was seen. Early ERGs (Fig. 3A) were characterized a dominant a-wave, and the b-wave developed during the next $30 \mathrm{~min}$ [14]. The superimposed traces in Fig. 3B reveal that over time $(60-215 \mathrm{~min})$ the amplitude did not decrease much, but the implicit time got shorter and the shape of the b-wave changed indicating that the transretinal signalling varied (compare to later results with the different mouse mutants, especially the ERGs from $\mathrm{Ca}_{\mathrm{v}} 2.3$-deficient mice, which are lacking the later fraction of the b-wave [9]).

The major goal for murine ERG-recording was the demonstration of an increase of the bwave amplitude after the superfusion of low $\mathrm{NiCl}_{2}(10-30 \mu \mathrm{M})$. Under these conditions (15 $\mu \mathrm{M} \mathrm{NiCl}_{2}$ ) the ERG b-wave amplitude of the isolated bovine retina was increased up to 1.5fold [3]. For the bovine retina it was concluded that the pharmacoresistant $\mathrm{Ca}^{2+}$ channel $\mathrm{Ca}_{\mathrm{v}} 2.3$ may trigger the GABA release necessary for reciprocal signalling backwards to the bipolar neurons [10]. This conclusion should be validated or disproven in mouse models with selective $\mathrm{Ca}^{2+}$ channel inactivation, either lacking $\mathrm{Ca}_{v} 2.3$ or $\mathrm{Ca}_{\mathrm{v}} 3.2$ or even both subunits of voltage-gated $\mathrm{Ca}^{2+}$ channels. Therefore, the murine retina had to be isolated in a way that not only the basal signal transduction but also the reciprocal signalling would be conserved over time. Under these conditions, retinas from $\mathrm{Ca}_{\mathrm{v}} 2.3$-competent and $\mathrm{Ca}_{\mathrm{v}} 2.3$ deficient mice were isolated and their sensitivity towards $\mathrm{NiCl}_{2}(15$ and $30 \mu \mathrm{M})$ was analysed and compared between different genotypes [14]. For the ERGs from $\mathrm{Ca}_{\mathrm{v}} 2.3-$ competent mice, the data for $30 \mu \mathrm{M} \mathrm{NiCl}_{2}$ are summarized (Tab. 1).

\begin{tabular}{|c|c|c|c|c|c|}
\hline Exp. \# & $\begin{array}{c}\text { Before } \mathrm{NiCl}_{2}: \\
\text { Amplitude, } \mu \mathrm{V}\end{array}$ & $\begin{array}{c}\text { After NiCl2, } \\
30 \mu \mathrm{M}: \\
\text { Amplitude, } \mu \mathrm{V}\end{array}$ & $\begin{array}{c}\text { Washout: } \\
\text { Amplitude, } \mu \mathrm{V}\end{array}$ & $\begin{array}{c}\text { Ratio 1: } \\
\text { under } \mathrm{NiCl}_{2} \\
\text { before } \mathrm{NiCl}_{2}\end{array}$ & $\begin{array}{c}\text { Ratio 2: } \\
\text { under } \mathrm{NiCl}_{2} \\
\text { after Washout }\end{array}$ \\
\hline 1 & 6,15 & 11,18 & 6,87 & 1,82 & 1,63 \\
\hline 2 & 14,88 & 16,63 & 11,58 & 1,12 & 1,44 \\
\hline 3 & 4,97 & 7,63 & 4,65 & 1,54 & 1,64 \\
\hline 4 & 9,70 & 16,2 & 9,28 & 1,67 & 1,75 \\
\hline 5 & 5,90 & 9,0 & 6,23 & 1,53 & 1,44 \\
\hline 7 & 9,82 & 13,91 & 10,85 & 1,42 & 1,28 \\
\hline 8 & 6,55 & 8,39 & 7,44 & 1,28 & 1,13 \\
\hline 9 & 24,98 & 20,27 & 22,72 & 0,81 & 0,89 \\
\hline & 98,30 & 142,8 & 111,2 & 1,45 & 1,23 \\
\hline & & & & & 1,40 \\
\hline & & & Mean: & 0,3 & 0,28 \\
\hline & & & Stdev & 0,1 & 0,09 \\
\hline
\end{tabular}

Table 1. Development of b-wave amplitude after a 4 hour preincubation period for $\mathrm{Ca}_{\mathrm{v}} 2.3-$ competent mice by superfusing nutrient solution (= before $\left.\mathrm{NiCl}_{2}\right), 30 \mu \mathrm{M} \mathrm{NiCl}_{2}$ for $30 \mathrm{~min}(=$ after $\mathrm{NiCl}_{2}$ ), and by washing out the $\mathrm{NiCl}_{2}$ (= washout). Note, such a reversible increase of the b-wave amplitude, as shown for 9 experiments, was not always observed. In nearly the same number of experiments, no significant increase was detected, which may be attributed to the 4 hour preincubation period, during which reciprocal signalling was partially reduced or completely lost for unknown reasons.

As the full ERG-response with "healthy" b-waves was only achieved after a prolonged incubation period of 4 hours, we were afraid and realized that the capacity for maximal 
reciprocal signalling was partially or fully lost during such a preincubation. The consecutive large scatter for $\mathrm{Ni}^{2+}$-mediated stimulation of the b-wave amplitude led us to conclusion to modify the recording procedure for a more stable transretinal signalling.

\subsubsection{Retina isolation under gentle conditions without a preincubation period}

To overcome any variable loss of reciprocal signalling, the murine retina was isolated again by the more gentle procedure as outlined before [14]. The adaptation period however was skipped to avoid any loss of reciprocal signalling. Early ERG recordings, which were still dominated by the photoreceptor response, were digitalized and stored, and mean values were calculated for the response before adding any $\mathrm{NiCl}_{2}$. Thereafter, $\mathrm{NiCl}_{2}$ superfusion (15 $\mu \mathrm{M})$ was initiated within the first $15-20 \mathrm{~min}$ after introducing the retina segments into the recording chamber. The $\mathrm{NiCl}_{2}$ application routinely lasts for $30 \mathrm{~min}$, a time, after which a new equilibrium was reached and stable full ERG responses were recorded. From those ERG traces a mean trace curve was calculated and the mean ERG trace without $\mathrm{NiCl}_{2}$ superfusion was subtracted from the mean trace under $\mathrm{NiCl}_{2}$. Such difference-ERG traces were normalized and compared between different genotypes [9].

To our surprise, even the photoreceptor response differed between the two mouse lines either lacking $\mathrm{Ca}_{\mathrm{v}} 3.2$ (including the double knockout) and the $\mathrm{Ca}_{\mathrm{v}} 2.3$-competent or -deficient mouse line. The larger hyperpolarization at the beginning of each experiment for $\mathrm{Ca}_{\mathrm{v}} 3.2-$ deficient mice or double knockout mice was the reason that the amplitude of the differenceERG was much larger than in retinas from $\mathrm{Ca}_{\mathrm{v}} 2.3$-competent or -deficient mice. Most interesting, however, was the result deduced from implicit times of the normalized difference-ERGs. Obviously, $\mathrm{Ca}_{\mathrm{v}} 2.3$ / R-type and $\mathrm{Ca}_{\mathrm{v}} 3.2$ / T-type $\mathrm{Ca}^{2+}$ channels may contribute to different fractions of the signal transduction in the retinal network. In $\mathrm{Ca}_{\mathrm{v}} 2.3-$ deficient mice, the implicit time for the apparent b-wave is significantly shorter (346 $\pm 12 \mathrm{~ms}$; $\mathrm{n}=8$ retinas) than in $\mathrm{Ca}_{\mathrm{v}} 2.3$-competent mice $(474 \pm 27$ ms; $\mathrm{n}=5$ retinas; $\mathrm{p}<0.001)$, which implies that the later b-wave fraction, which is missing in the $\mathrm{Ca}_{\mathrm{v}} 2.3$-deficient mice, would be carried in $\mathrm{Ca}_{\mathrm{v}} 2.3$-compentent mice by the pharmacoresistant R-type channel triggering synaptic neurotransmitter release. This interpretation is in line with the assumption [10] that $\mathrm{Ca}_{\mathrm{v}} 2.3$ may act in the synapse of a third order neuron, e.g. after the bipolar - amacrine synapse, while $\mathrm{Ca}_{\mathrm{v}} 3.2$ may rather be responsible for a T-type triggered neurotransmitter release in the bipolar - amacrine synapse. T-type $\mathrm{Ca}^{2+}$ currents were routinely identified in these bipolar neurons [15-17].

The inactivation of $\mathrm{Ca}^{2+}$ channel genes could also disturb the overall retinal organisation. However, at least the inactivation of $\mathrm{Ca}_{\mathrm{v}} 2.3$ does not disturb macroscopic structures in the retina as evaluated by histochemical staining (Fig. 4). Visual inspection and quantification of the thickness for retinal layers confirmed that no massive loss of neurons has occurred, which may also be true for the other knockout models.

\subsection{Tricine-containing nutrient solution to chelate traces of divalent heavy metals}

The use of $\mathrm{Ni}^{2+}$ as $\mathrm{Ca}^{2+}$ channel antagonist for $\mathrm{R}$ - and T-type $\mathrm{Ca}^{2+}$-channels has a long tradition [18;19]. Only recently zinc and copper ions have been recognized as important endogenous modulators of neuronal excitability [20], and the most $\mathrm{Ni}^{2+}$-sensitive $\mathrm{Ca}^{2+}$ channels were also characterized for its capability to be blocked by these native heavy metal cations [21-24]. The disturbance of their homoeostasis may be responsible for several neurological diseases as for example Morbus Alzheimer [25;26]. Much more is known for 
the physiological role of $\mathrm{Zn}^{2+}$ than for $\mathrm{Cu}^{2+}$, which proves to be effective (submicromolar) even in lower concentrations than $\mathrm{Zn}^{2+}$.

A. $\mathrm{Ca}_{\mathbf{v}} 2 \cdot 3(+\mid+)$ control mice
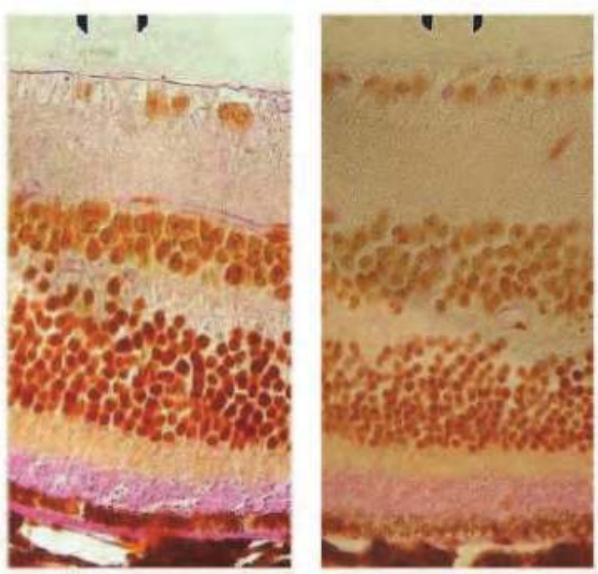

C.
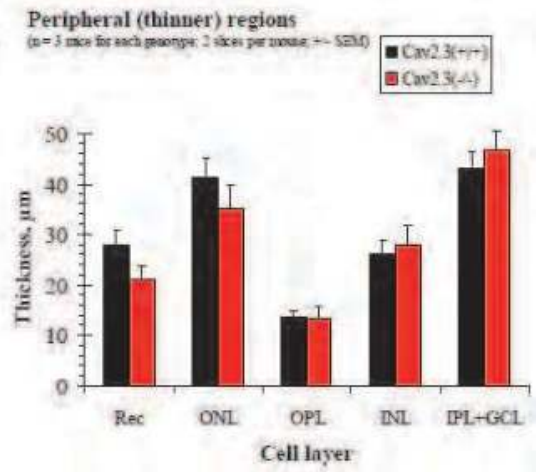

\section{B. Ca 2 2-3-deficient mice}
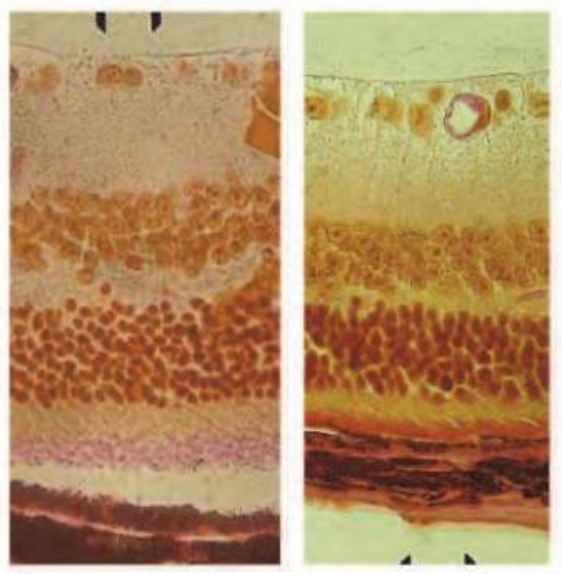

D. Central (thicker) regions

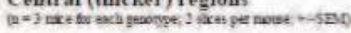

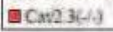

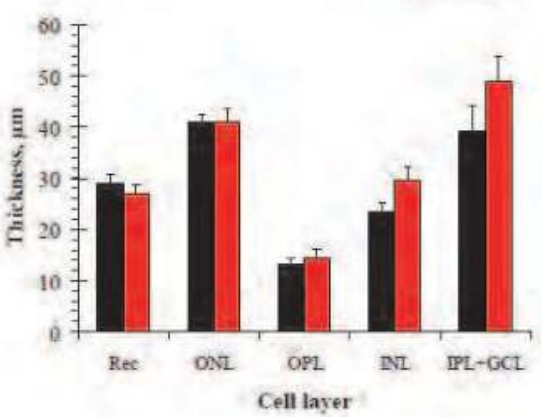

Fig. 4. Comparison of thicknesses in retinal cross sections obtained from control and $\mathrm{Ca}_{\mathrm{v}} 2.3-$ deficient mice. Light micrographs were taken from thicker (more central) regions and from thinner (more peripheral) regions away from the optical nerve head. Each layer is identified by its abbreviations $(\operatorname{Rec}=$ photoreceptors; $\mathrm{ONL}=$ outer nuclear layer; $\mathrm{OPL}=$ outer plexiform layer; INL = inner nuclear layer; IPL + GCL: inner plexiform layer and granular cell layer were summarized for quantification; data were produced by Mehran Maghsoodian and Petra Müller). A. Retinal sections from control female mice at the age of 34 month. B. Retinal sections from $\mathrm{Ca}_{\mathrm{v}} 2.3$-deficient female mice at the same age of 34 month. C \& D.: Quantification of thicknesses for individual retinal layers for controls and KO's. 
The effect of $\mathrm{ZnCl}_{2}(10-15 \mu \mathrm{M})$ on transretinal signalling resembles the effect of $\mathrm{NiCl}_{2}$, which was investigated in detail for the isolated bovine retina [11].

The second most abundant trace element in the human body is represented by $\mathrm{Zn}^{2+}$. In total it reaches up to two grams in adult humans. Most $\mathrm{Zn}^{2+}$ in the body is located intracellularily. But as only a small labile portion in the liver may be available during $\mathrm{Zn}^{2+}$ deficiency, a regular dietary supply of $\mathrm{Zn}^{2+}$ during growth and aging is needed [27].

After $\mathrm{Zn}^{2+}$ deficiency, the multitude of physiological roles for $\mathrm{Zn}^{2+}$ are best seen, which include anorexia, retarded growth, weight loss, impaired immune function, delayed sexual maturation, testicular atrophy, epidermal hyperkeratinization, alopecia, hypogeuisa, and night blindness [27;28]. In ocular tissues, the concentration of $\mathrm{Zn}^{2+}$ is unusually high when compared to other tissues. $\mathrm{Zn}^{2+}$ was localized in retina, chorioid, ciliary body, iris, optic nerve, sclera, cornea, and lens [27;29].

As soon as the function of $\mathrm{Cu}^{2+}$ would also be investigated, contaminations of submicromolar heavy metal cations may count for the validity of experiments in the future. To test a well known buffer system, which can be used to calibrate the desired cation concentration, tricine was added in various amounts $(15 \mathrm{mM}, 10 \mathrm{mM}$, and $5 \mathrm{mM})$ to the normally used nutrient solution. The bovine retina was used in these experiments. While 15 and $10 \mathrm{mM}$ inhibited the b-wave response, no substantial change was observed at $5 \mathrm{mM}$ tricine. Sometimes we observed a slight decrease of the b-wave amplitude, which may be attributed to heavy metal contaminations in the nutrient solution. After a chelation of traces by tricine, the effect of $\mathrm{NiCl}_{2}(15 \mu \mathrm{M})$ was analysed leading to a similar and transient increase of the bwave response (Fig. 5).

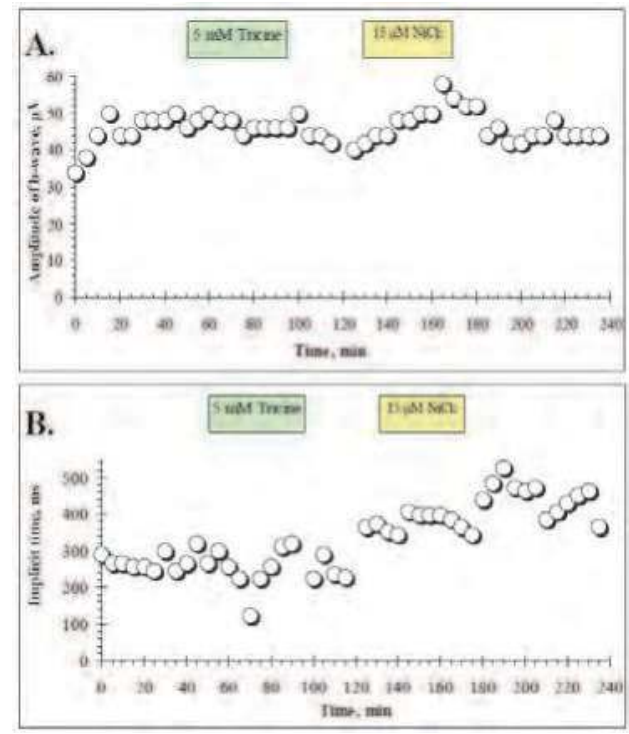

Fig. 5. ERG recordings from the isolated bovine retina. After isolation of a standard retina segment, the retina was equilibrated for at least $30 \mathrm{~min}$. A. During the superfusion of $5 \mathrm{mM}$ tricine buffer added to the normal nutrient solution, no lasting change of $b$-wave response was observed. Tricine was washed and exchanged to normal nutrient solution including $\mathrm{NiCl}_{2}(15 \mu \mathrm{M})$, leading to a transient increase of the b-wave response. B. Implicit times increase mostly after superfusion with $\mathrm{NiCl}_{2}$. 


\subsection{Stability testing for murine ERG responses under high intensity light conditions}

So far, murine ERGs were recorded under low light intensity (63 mlx for $0.5 \mathrm{sec})$. But the testing of higher light intensities may be needed, because reciprocal signalling should be more pronounced at elevated light intensities, if the reciprocal signalling participates in light/dark adaptation. Therefore, we analysed the effect of increasing light intensities on the photoreceptor response of the isolated murine retina (Fig. 6).
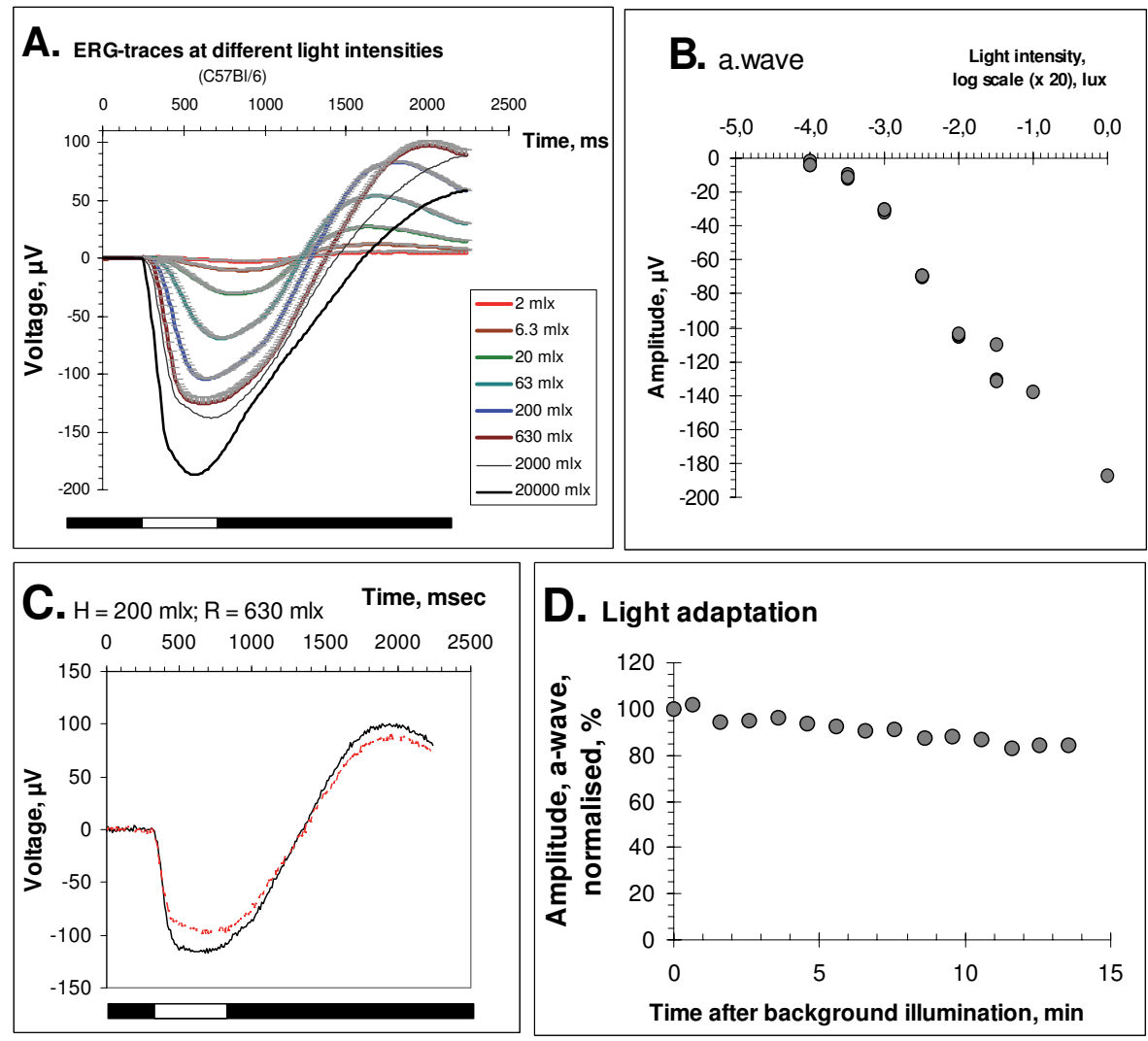

Fig. 6. Murine ERGs were recorded after gentle retina isolation without a preincubation period. Light flashes were given in 3 min intervals interrupted by darkness. Light stimuli were at various light intensities for $0.5 \mathrm{sec}$ (light bar at the bottom of each figure).

Temperature was $27.5^{\circ} \mathrm{C}$. In some panels the background light intensity $(=\mathrm{H})$, and the stimulus intensity $(=\mathrm{R})$ is given. A. Early registration of ERGs in the absence of $\mathrm{NiCl}_{2}$. Recording was started within $30 \mathrm{~min}$ after loading the recording chamber. B. Light intensity - response curve for the apparent a-wave amplitude (data taken from the ERG records in panel A). The semi-logarithmic plot shows a linear increase up to the highest light intensity tested (2 mlx - $20 \mathrm{~lx})$. C. Superposition of ERG traces before (solid black line) and $15 \mathrm{~min}$ after light adaptation (fine dashed red line) under continuous light (200 mlx). Stimulus light intensity was $630 \mathrm{mlx}$. Note the minor reduction of the apparent a-wave may be attributed to a slowly increasing b-wave, which gets more pronounced after $\mathrm{NiCl}_{2}$ application (see Fig. 7). D. Time course of light adaptation under the conditions as described in panel C. 

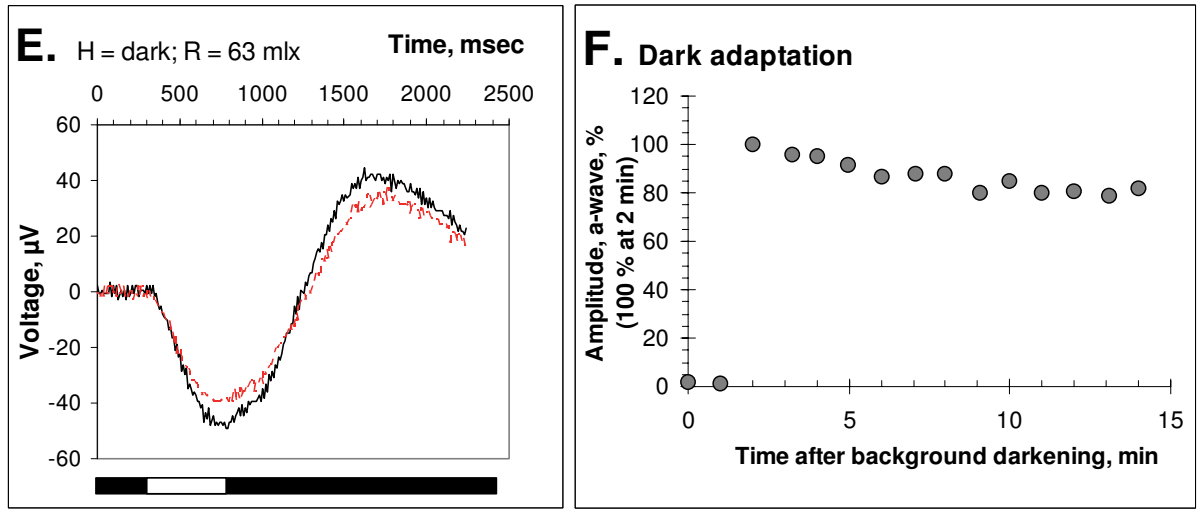

G. ERG-traces at different light intensities (C57B/6)

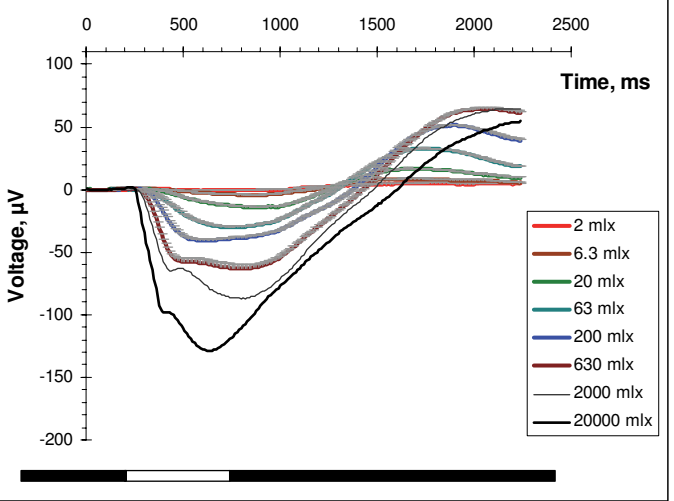

H. Apparent a-wave Light intensity,

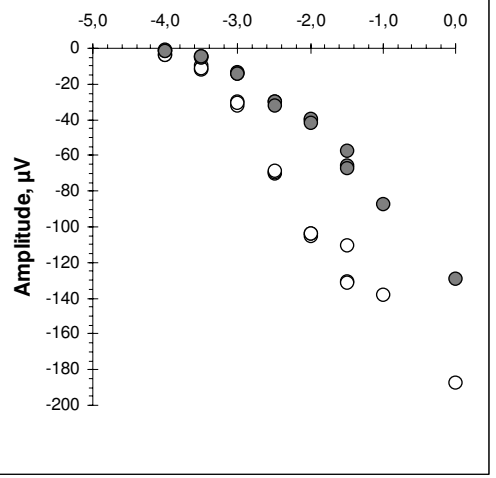

Fig. 6 (continued). E. After the light adaptation for $15 \mathrm{~min}$ (see panel D), dark adaption was tested for the stability of the photoreceptor response. Superposition of ERG traces $6 \mathrm{~min}$ (solid black line) and 15 min after dark adaptation (fine dashed red line). Stimulus light intensity was $63 \mathrm{mlx}$. Again, a minor reduction of the apparent a-wave may be attributed to a slowly increasing b-wave, which gets more pronounced after $\mathrm{NiCl}_{2}$ application (see Fig. 7). Note the stimulus light intensity under scotopic conditions was $1 / 10^{\text {th }}$ of that during light adaptation in panel D. F. Time course of the photoreceptor response during $15 \mathrm{~min}$ dark adaptation using a stimulus light intensity of $6.3 \mathrm{mlx}$ (at 0 and $3 \mathrm{~min}$ ) and of $63 \mathrm{mlx}$ for the remaining light flashes. Note the flash light intensity during the first $6 \mathrm{~min}$ was reduced to ensure dark adaptation to start fast. G. Superposition of ERG responses (dominated by awave) from different light intensities ( $2 \mathrm{mlx}-20 \mathrm{~lx})$. Especially during higher light intensities (200 mlx - $20 \mathrm{~lx}$ ) a small b-wave gets visible. H. Light intensity - response curve for the apparent a-wave amplitude (filled circles; data taken from the ERG records in panel $\mathrm{G})$. The semi-logarithmic plot shows a near linear increase up to the highest light intensity tested ( $2 \mathrm{mlx}-20 \mathrm{~lx})$, which reveals lower apparent a-wave amplitudes as during the first regime (open circles; data are identical to panel B). Threshold values for light intensities are similar in both regimes. 
During an experimental regime of early dose-response (Fig. 6A, 6B), light (Fig. 6C, 6D) and dark adaptation (Fig. 6E, 6F), and late dose-response (Fig. 6G, 6H), it gets obvious that the isolated murine retina yields rather stable photoreceptor responses, which are only slightly reduced by the slowly growing $b$-wave. A faster development of the b-wave response can be achieved by adding $\mathrm{NiCl}_{2}$. The superfusion of $15 \mu \mathrm{M} \mathrm{NiCl}$ leads within 30 min to a fast increase of the developing b-wave. The ERG traces before and after $\mathrm{NiCl}_{2}$ superfusion indicate that during this period b-wave gets maximally increased (Fig. 7), as reported recently [9].

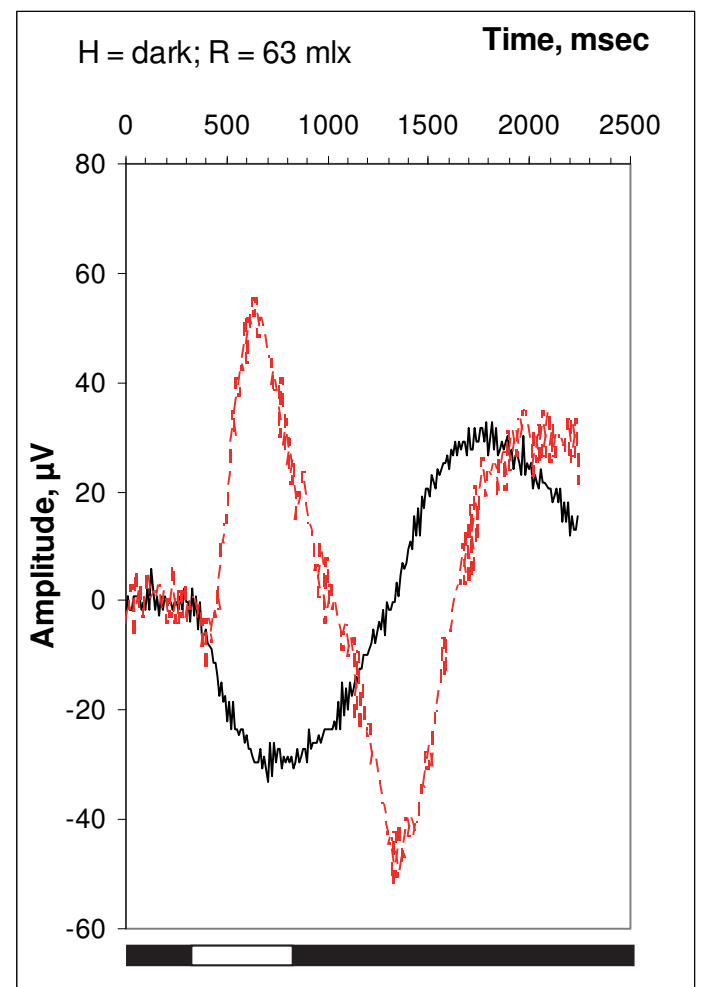

Fig. 7. Development of b-wave by $\mathrm{NiCl}_{2}$ application. Superposition of ERG traces before (black solid line) and after $\mathrm{NiCl}_{2}$ superfusion $(15 \mu \mathrm{M}$; red dashed line). The increase is still half-maximal within 6 min of $\mathrm{NiCl}_{2}$ superfusion. Note, after full development of b-wave, it superimposes nearly completely the a-wave response, as it is expected for a light intensity of $63 \mathrm{mlx}$ (compare [14]). $\mathrm{H}=$ background in darkness in between each light flash. $\mathrm{R}=$ stimulus intensity.

To test the stability of the isolated murine retina for its transretinal signalling capability (Fig. 8), the b-wave amplitude was recorded and used as the readout during similar experiments as it was performed for photoreceptor responses. The light induced stress was even increased by recording the light intensity - response curve under continuous background light first at $630 \mathrm{mlx}$ (not shown) and thereafter at $2000 \mathrm{mlx}$ (Fig. 8E, 8F). 


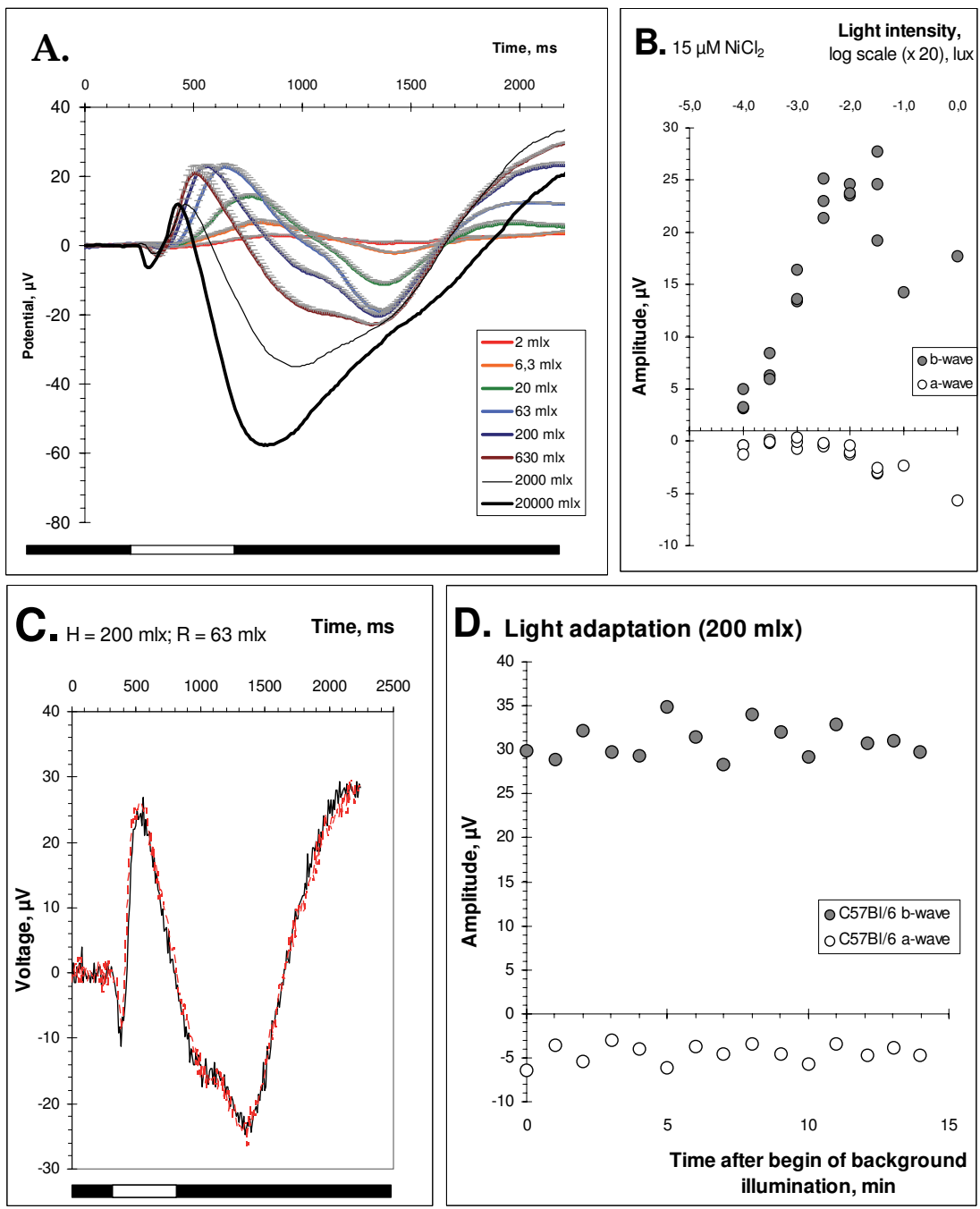

Fig. 8. Murine ERGs were recorded after gentle retina isolation without a preincubation period in the presence of $15 \mu \mathrm{M} \mathrm{NiCl}_{2}$. Light flashes were given after $3 \mathrm{~min}$ at various light intensities for $0.5 \mathrm{sec}$. Background illumination as indicated in each panel. Temperature was $27.5^{\circ} \mathrm{C}$. A. Recording was continued without delay after the b-wave was reached (Fig. 7). Superposition of individual ERG traces at the indicated light intensities. Background was in darkness. B. Light intensity - response curve for the b-wave amplitude (data taken from the ERG records in panel A). The semi-logarithmic plot shows an optimum of the b-wave response between 63 and $630 \mathrm{mlx}$. C. Superposition of ERG traces recorded at $63 \mathrm{mlx}$ stimulus light before (solid black line) and $15 \mathrm{~min}$ of light adaptation (fine dashed red line) under continuous light $(200 \mathrm{mlx})$. Stimulus light intensity was $63 \mathrm{mlx}$. Note the ERG traces are nearly identical at both time points. D. Time course of light adaptation for apparent aand $\mathrm{b}$-wave under the conditions as described in panel $\mathrm{C}$. 

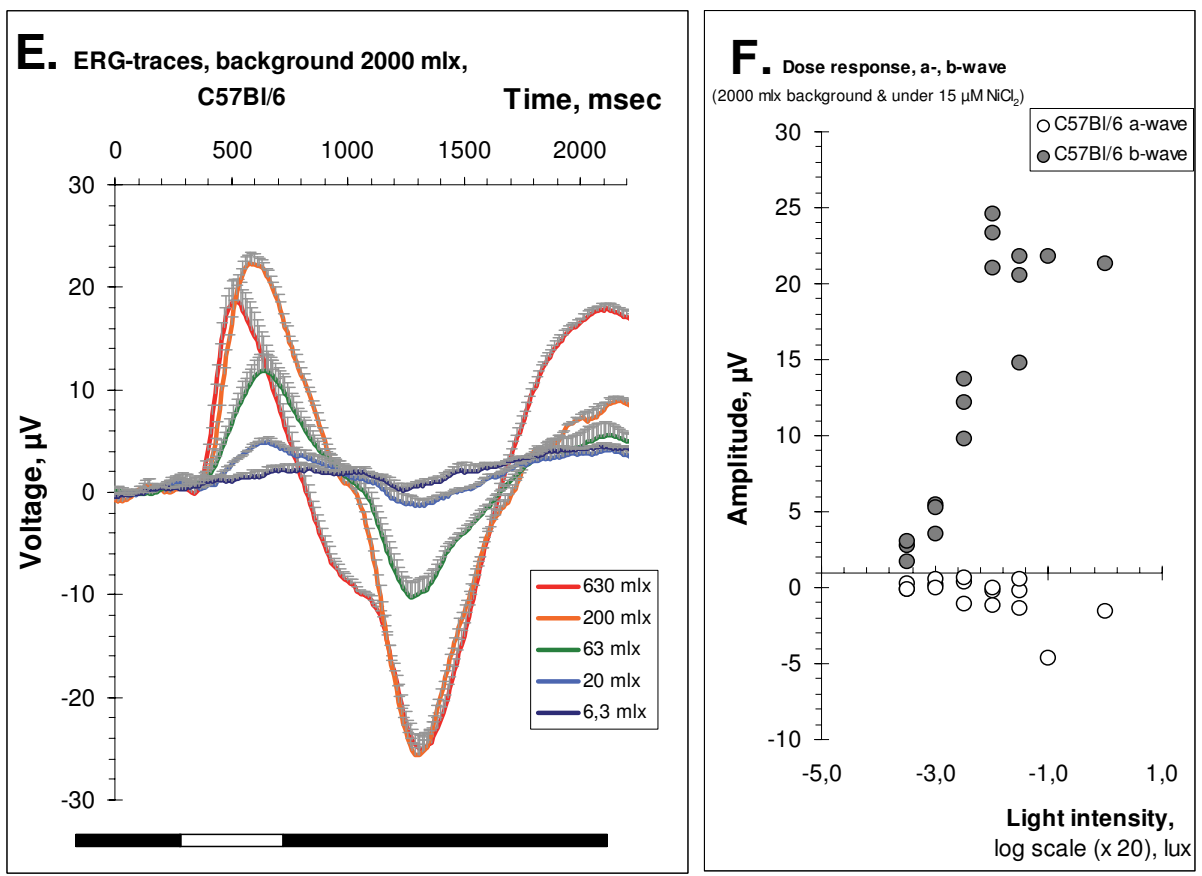

Fig. 8 (continued). E. After the light adaptation for $15 \mathrm{~min}$, the light intensity-response was recorded first with $630 \mathrm{mlx}$ background light (not shown) and next with $2000 \mathrm{mlx}$ background light. Superposition of ERG traces for the stimulus light intensities as indicated. F. Light intensity - response curve for the b-wave amplitude (data taken from the ERG records in panel E). The semi-logarithmic plot shows an optimum of the b-wave response at $200 \mathrm{mlx}$.

Increasing the light intensity beyond 63 to $630 \mathrm{mlx}$ caused a reduction of the b-wave amplitude as reported in the literature, and reflecting the process of light adaptation. Consecutively, the apparent a-wave amplitude gets increased (Fig. 8B). For the b-wave, the implicit time gets shorter during increased light intensities. Interestingly, under these conditions of $15 \mathrm{~min}$ continuous background light $(200 \mathrm{mlx})$, the stability of the b-wave response is remarkable. Even more astonishing is the observation that under 630 and 2000 $\mathrm{mlx}$ background light, the b-wave responses continue to be very pronounced tolerating the increased light intensity at the recording chamber.

\section{Conclusion}

The transfer of the ERG recording technique from the bovine retina model to the various murine knockout models is possible, and the higher sensitivity of the murine retina towards ischemia maybe overcome by a more gentle preparation technique as outlined in detail [14]. Future investigations of the murine retina from different mouse models may benefit from such an isolation procedure. 
Besides ERG recordings additional electrophysiological recording techniques (e.g. patch clamp registration) will be needed to characterize signalling through retinal circuits.

\section{Acknowledgment}

We thank Priv.-Doz. Dr. Matthias Lüke, Dr. Siarhei A. Siapich for their excellent and permanent assistance during the work with the bovine retina, which is an important prerequisite for the transfer to the murine retina. The authors would also like to thank Nadeen Albanna (animation), Renate Clemens (genotyping and breeding of mice), Mehran Maghsoodian and Petra Müller (retinal IHC) for their support, as well as the animal keepers of the central facility for their excellent and permanent assistance. This work was financially supported by the Köln Fortune Programme of the Faculty of Medicine, University of Cologne (to MA, WA and MB) and by the Center for Molecular Medicine Cologne (CMMC, to TS and JH, Faculty of Medicine, University of Cologne).

\section{References}

[1] Walter P \& Sickel W: Identification of fast spurts of pyridine nucleotide oxidation evoked by light stimulation in the isolated perfused vertebrate retina. Graefes Arch Clin. Exp. Ophthalmol. 1994;232: 318-323.

[2] Lüke C, Walter P, Bartz-Schmidt KU, Brunner R, Heimann K \& Sickel W: Effects of Antiviral Agents on Retinal Function in Vertebrate Retina. Adv. Ocul. Tox. 1997;13: 107-112.

[3] Lüke M, Henry M, Lingohr T, Maghsoodian M, Hescheler J, Sickel W \& Schneider T: A $\mathrm{Ni}^{2+}$-sensitive component of the ERG-b-wave from the isolated bovine retina is related to E-type voltage-gated $\mathrm{Ca}^{2+}$ channels. Graefes Arch. Clin. Exp. Ophthalmol. 2005;243: 933-941.

[4] Lüke M, Weiergräber M, Brand C, Siapich SA, Banat M, Hescheler J, Lüke C \& Schneider $\mathrm{T}$ : The isolated perfused bovine retina - a sensitive tool for pharmacological research on retinal function. Brain Res. Brain Res. Protoc. 2005;16: 27-36.

[5] Green DG \& Kapousta-Bruneau NV: Electrophysiological properties of a new isolated rat retina preparation. Vision Res. 1999;39: 2165-2177.

[6] Green DG, Guo H \& Pillers DA: Normal photoresponses and altered b-wave responses to $\mathrm{APB}$ in the $\mathrm{mdx}(\mathrm{Cv} 3)$ mouse isolated retina ERG supports role for dystrophin in synaptic transmission. Vis. Neurosci 2004;21: 739-747.

[7] Sickel W: Respiratory and electrical responses to light stimulation in the retina of the frog. Science 1965;148: 648-651.

[8] Sickel W. (1972) Retinal Metabolism in Dark and Light. In Handbook of Sensory Physiology (Autrum,H., Jung,R., Loewenstein,W.R., MacKay,D.M. \& Teuber,H.L., eds), pp. 667-727. Springer-Verlag, Berlin, Heidelberg, New York.

[9] Alnawaiseh M, Albanna W, Chen C-C, Campbell KP, Hescheler J, Lüke M \& Schneider T: Two separate $\mathrm{Ni}^{2+}$ sensitive voltage-gated $\mathrm{Ca}^{2+}$ channels modulate transretinal signalling in the isolated murine retina. Acta Ophthalmologica 2011; in press.

[10] Siapich SA, Banat M, Albanna W, Hescheler J, Lüke M \& Schneider T: Antagonists of ionotropic gamma-aminobutyric acid receptors impair the $\mathrm{NiCl} 2$-mediated stimulation of the electroretinogramm b-wave amplitude from the isolated superfused vertebrate retina. Acta Ophthalmol. 2009;87: 854-865. 
[11] Siapich SA, Wrubel H, Albanna W, Hescheler J, Weiergräber M, Lüke M \& Schneider T: Effect of $\mathrm{ZnCl} 2$ and chelation of zinc ions by $\mathrm{N}, \mathrm{N}$-diethyldithiocarbamate (DEDTC) on the ERG b-wave amplitude from the isolated and superfused vertebrate retina. Curr. Eye Res. 2010;35: 322-334.

[12] Banat M, Lüke M, Siapich SA, Hescheler J, Weiergräber M \& Schneider T: The dihydropyridine isradipine inhibits the murine but not the bovine A-wave response of the electroretinogram. Acta Ophthalmol. 2008;86: 676-682.

[13] Hanawa I \& Tateishi T: The effect of aspartate on the electroretinogram of the vertebrate retina. Experientia 1970;26: 1311-1312.

[14] Albanna W, Banat M, Albanna N, Alnawaiseh M, Siapich SA, Igelmund P, Weiergraber M, Luke M \& Schneider T: Longer lasting electroretinographic recordings from the isolated and superfused murine retina. Graefes Arch. Clin. Exp. Ophthalmol. 2009;247: 1339-1352.

[15] Pan ZH: Differential expression of high- and two types of low-voltage-activated calcium currents in rod and cone bipolar cells of the rat retina. J. Neurophysiol. 2000;83: 513527.

[16] Pan ZH, Hu HJ, Perring P \& Andrade R: T-type $\mathrm{Ca}(2+)$ channels mediate neurotransmitter release in retinal bipolar cells. Neuron 2001;32: 89-98.

[17] Hu C, Bi A \& Pan ZH: Differential expression of three T-type calcium channels in retinal bipolar cells in rats. Vis. Neurosci. 2009;26: 177-187.

[18] Kostyuk PG: Calcium channels in the neuronal membrane. Biochim. Biophys. Acta 1981;650: 128-150.

[19] Lacinova L: Voltage-dependent calcium channels. Gen. Physiol Biophys. 2005;24 Suppl $1: 1-78$.

[20] Mathie A, Sutton GL, Clarke CE \& Veale EL: Zinc and copper: pharmacological probes and endogenous modulators of neuronal excitability. Pharmacol. Ther. 2006;111: 567-583.

[21] Castelli L, Tanzi F, Taglietti V \& Magistretti J: Cu2+, Co2+, and Mn2+ modify the gating kinetics of high-voltage-activated $\mathrm{Ca} 2+$ channels in rat palaeocortical neurons. J. Membr. Biol. 2003;195: 121-136.

[22] Magistretti J, Castelli L, Taglietti V \& Tanzi F: Dual effect of Zn2+ on multiple types of voltage-dependent $\mathrm{Ca} 2+$ currents in rat palaeocortical neurons. Neuroscience 2003;117: 249-264.

[23] Kang HW, Park JY, Jeong SW, Kim JA, Moon HJ, Perez-Reyes E \& Lee JH: A molecular determinant of nickel inhibition in Cav3.2 T-type calcium channels. J. Biol. Chem. 2006;281: 4823-4830.

[24] Kang HW, Vitko I, Lee SS, Perez-Reyes E \& Lee JH: Structural determinants of the high affinity extracellular zinc binding site on Cav3.2 T-type calcium channels. J. Biol. Chem. 2010;285: 3271-3281.

[25] Lovell MA: A potential role for alterations of zinc and zinc transport proteins in the progression of Alzheimer's disease. J. Alzheimers. Dis. 2009;16: 471-483.

[26] Jomova K, Vondrakova D, Lawson M \& Valko M: Metals, oxidative stress and neurodegenerative disorders. Mol. Cell Biochem. 2010;345: 91-104.

[27] Grahn BH, Paterson PG, Gottschall-Pass KT \& Zhang Z: Zinc and the eye. J. Am. Coll. Nutr. 2001;20: 106-118.

[28] Aggett PJ \& Comerford JG: Zinc and human health. Nutr. Rev. 1995;53: S16-S22.

[29] Karcioglu ZA: Zinc in the eye. Surv. Ophthalmol. 1982;27: 114-122. 


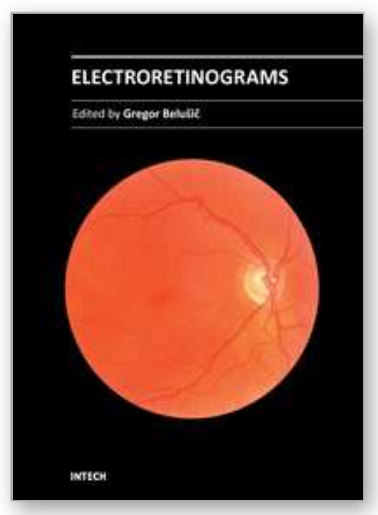

\author{
Electroretinograms \\ Edited by Dr. Gregor Belusic
}

ISBN 978-953-307-383-5

Hard cover, 238 pages

Publisher InTech

Published online 09, August, 2011

Published in print edition August, 2011

Electroretinography (ERG) is a non-invasive electrophysiological method which provides objective information about the function of the retina. Advanced ERG allows to assay the different types of retinal receptors and neurons in human and animal models. This book presents contributions on the recent state of the ERG. The book is divided into three parts. The first, methodological part, reviews standard methods and normatives of human ERG, reports about the advanced spatial, temporal and spectral methods of stimulation in human ERG, and deals with the analysis of the multifocal ERG signal. The second part deals with the ERG in different diseases of the human visual system and in diabetes. The third part presents the ERG in the standard animal models of human retinal disease: mouse, rat, macaque and fruitfly.

\title{
How to reference
}

In order to correctly reference this scholarly work, feel free to copy and paste the following:

Alnawaiseh Maged, Albanna Walid, Banat Mohammed, Abumuaileq Ramzi, Hescheler Jürgen and Schneider Toni (2011). Electroretinographic Recordings from the Isolated and Superfused Murine Retina, Electroretinograms, Dr. Gregor Belusic (Ed.), ISBN: 978-953-307-383-5, InTech, Available from: http://www.intechopen.com/books/electroretinograms/electroretinographic-recordings-from-the-isolated-andsuperfused-murine-retina

\section{INTECH}

open science | open minds

\author{
InTech Europe \\ University Campus STeP Ri \\ Slavka Krautzeka 83/A \\ 51000 Rijeka, Croatia \\ Phone: +385 (51) 770447 \\ Fax: +385 (51) 686166 \\ www.intechopen.com
}

\author{
InTech China \\ Unit 405, Office Block, Hotel Equatorial Shanghai \\ No.65, Yan An Road (West), Shanghai, 200040, China \\ 中国上海市延安西路65号上海国际贵都大饭店办公楼405单元 \\ Phone: +86-21-62489820 \\ Fax: +86-21-62489821
}


(C) 2011 The Author(s). Licensee IntechOpen. This chapter is distributed under the terms of the Creative Commons Attribution-NonCommercialShareAlike-3.0 License, which permits use, distribution and reproduction for non-commercial purposes, provided the original is properly cited and derivative works building on this content are distributed under the same license. 